\title{
EFISIENSI PENYALURAN KREDIT RITEL KOMERSIAL TERHADAP SEKTOR UMKM DI BRI (STUDI KASUS DI BRI KANTOR WILAYAH JAKARTA 3)
}

\author{
EFFICIENCY OF COMMERCIAL RETAIL CREDIT DISTRIBUTION ON SME SECTOR IN BRI \\ (A CASE STUDY OF BRI REGIONAL OFFICE BRI JAKARTA AREA 3)
}

\author{
Bagus Ary Wibowo*), Amzul Rifin ${ }^{* *)}$, dan Sadikin Kuswanto*) \\ *) PT Bank Rakyat Indonesia (Persero), Tbk \\ Jl. Jendral Sudirman Kav 44-46, Jakarta \\ ${ }^{* * *}$ Departemen Agribisnis, Fakultas Ekonomi dan Manajemen, Institut Pertanian Bogor \\ Jl. Agatis Kampus IPB Darmaga, Bogor 16880 \\ ${ }^{* * *)}$ CDE Consulting Group \\ DKI Jakarta
}

\begin{abstract}
BRI Bank has its main focus to develop micro, small, and medium enterprises (UMKM). With the support of 18 Regional Offices, BRI has become the pioneer in distributing commercial retail credit. However, from 2010 to 2015, the percentage of BRI profit decreased. This research aimed to analyze the efficiency level and examine the factors affecting the commercial retail credit channeling in BRI Regional Office 3 to the SME sector. The research was conducted using DEA and Panel Regression methods with secondary data in the Financial Statements of BRI Jakarta Regional Office 3, yearend periods of 2013, 2014 and 2015. Based on the analysis conducted using the DEA method, the results indicated that 4 DMU units (Branch Offices) from the total of 36 DMU units; i.e. in Joglo, Sanggau, Singkawang and Tangerang Merdeka achieved their efficiency value in the year of 2013-2015 consistently; that is, they were able to complete the work correctly by using minimum inputs that produce maximum outputs. Based on the significant value, factors affecting the efficiency of banks include operational costs, NPL, credit growth, and realization of debtors. The control of input or cost, the increase of retail credit productivity, and good credit quality maintenance can influence the efficiency score of each work unit in Regional Office 3 of BRI Jakarta, so it can give profit contribution for the company.
\end{abstract}

Keywords: efficiency, BRI, credit, SME, DEA

\begin{abstract}
Abstrak: Bank BRI memiliki fokus utama untuk mengembangkan usaha mikro, kecil dan menengah (UMKM). Dengan dukungan 18 Kantor Wilayah (Kanwil) yang dimiliki menjadikan BRI pionir dalam menyalurkan kredit ritel komersial. Namun dari Tahun 2010 hingga Tahun 2015 persentase laba BRI terjadi penurunan. Bertujuan untuk menganalisis tingkat efisiensi dan mengetahui faktor yang memengaruhi penyaluran kredit ritel komersial Kanwil BRI Jakarta 3 kepada sektor UMKM menggunakan metode DEA dan Regresi Panel dengan data sekunder berupa Laporan Keuangan BRI Kanwil Jakarta 3 periode akhir Tahun 2013, 2014 dan 2015. Berdasarkan hasil analisa menggunakan metode DEA menunjukkan bahwa 4 unit DMU (Kantor Cabang) dari total 36 unit DMU, yaitu Joglo, Sanggau, Singkawang dan Tangerang Merdeka telah mencapai nilai efisiensi pada Tahun 2013-2015 secara konsisten yaitu dapat menyelesaikan pekerjaan secara benar dengan menggunakan input yang minimal menghasilkan output yang maksimal. Berdasarkan nilai signifikan faktor-faktor yang memengaruhi tingkat efisiensi perbankan, di antaranya adalah biaya operasional, NPL, pertumbuhan kredit dan realisasi debitur. Pengendalian sisi input atau biaya, peningkatan produktifitas kredit ritel dan menjaga kualitas kredit yang baik dapat memengaruhi skor efisiensi dari masing-masing unit kerja di Kanwil BRI Jakarta 3 sehingga dapat memberikan kontribusi laba bagi perusahaan.
\end{abstract}

Kata kunci: efisiensi, BRI, kredit, UMKM, DEA

\footnotetext{
${ }^{1}$ Alamat Korespondensi:

Email: bagus.roe@gmail.com
} 


\section{PENDAHULUAN}

Penyaluran kredit bagi bank merupakan suatu aset yang akan menghasilkan pendapatan bank baik berupa pendapatan bunga maupun pendapatan bagi hasil. Hal tersebut menjadikan porsi kredit dalam aset perbankan menjadi dominan. Menurut Manurung dan Raharja (2004) berdasarkan pengalaman empiris, dalam kondisi normal kredit bank kurang lebih $70 \%$ dari total aset sebuah bank. Pertumbuhan kredit perbankan nasional pada periode Agustus 2015 jika dibandingkan dengan periode Agustus 2014 tumbuh sebesar 11,19\% atau naik dari Agustus 2014 sebesar Rp3.522,27 trilyun menjadi sebesar Rp3.916,70 trilyun di Agustus 2015. Namun, kondisi perbankan masih cukup rentan resiko. Hal tersebut dapat dilihat dari peningkatan rasio kredit bermasalah terhadap total kredit (non performing loan) dari 2,3\% pada akhir tahun 2014 menjadi 2,9\% pa Agustus 2015 (http://www.bi.go.id).

Suatu bank yang efisien menunjukkan kemampuan yang lebih dalam melakukan pengelolaan secara maksimal. Penelitian yang dilakukan oleh Bonin et al. (2005) menyimpulkan bahwa ukuran suatu bank berpengaruh positif terhadap efisiensi. Artinya semakin besar suatu bank, maka akan semakin efisien karena dapat memaksimalkan economies of scale. Dalam dekade terakhir, penelitian mengenai tingkat kompetisi perbankan tidak hanya berhenti pada teridentifikasinya persaingan. Bahasan mengenai bagaimana dampak kompetisi terhadap kinerja bank menjadi topik penelitian yang menarik (Hafidz et al. 2013).

Schaeck dan Cihak (2008) berpendapat bahwa kompetisi antarbank mampu berpengaruh positif terhadap tingkat kesehatan melalui transmisi efisiensi. Dalam penelitiannya, dilakukan pengujian terhadap dua hipotesis, yakni The Competition Efficiency Hypothesis dan The Competition-Inefficiency Hypothesis. Hasil pengujian menunjukkan bahwa hipotesis pertama dapat dibuktikan. Artinya, kompetisi mampu menstimulasi bank menjadi lebih efisien dengan menciptakan harga yang kompetitif atau sama dengan marginal cost pada pasar persaingan sempurna. Boot dan Schmeijts (2005) berpendapat bahwa Korelasi negatif antara tingkat kompetisi dan efisiensi berdasarkan The CompetitionInefficiency Hypothesis dapat terjadi pada struktur perbankan dengan tingkat persaingan yang tinggi, loyalitas nasabah cenderung menurun sehingga hubungan antara nasabah dan bank menjadi kurang stabil dan lebih bersifat jangka pendek.
Penelitian efisiensi kantor cabang bank menggunakan Data Envelopment Analysis (DEA) sudah banyak dilakukan dan sangat bermanfaat untuk mengetahui dan memperbandingkan efisiensi relatif dari Decision Making Units (DMU). Namun penelitian efisiensi dengan analisis DEA di Indonesia lebih banyak pada perbandingan efisiensi antar bank belum sampai pada penelitian antar kantor wilayah, kantor cabang, kantor cabang pembantu atau kantor kas pada suatu bank tertentu seperti pada penelitian Zenios et al. (1999), Kurnia (2004), Beccalli et al. (2007), Kirkwood dan Nahm (2007), Sufian dan Majid (2007), Harjum dan Puspitasari (2007), Giokas (2008), Abidin dan Endri (2009), Gaganis et al. (2009), Wardani (2011), Pratama (2011), Fitria (2014), Heriyaldi dan Yusuf (2013), Widyastuti dan Armanto (2013), Mashal dan Ahmed (2015) Pengukuran efisiensi memberikan beberapa tujuan. Hal ini dapat membantu bank secara individu untuk melakukan perbandingan efisiensi relatifnya dengan praktek perbankan terbaik. Pengukuran efisiensi dapat membantu untuk melakukan evaluasi dampak dari berbagai kebijakan dalam reformasi keuangan dengan penambahan modal dan tahap berikutnya adalah berorientasi pada efisiensi (Reddy, 2004; Dong dan Alen, 2004).

Ketentuan suku bunga LPS saat ini 7\% dan juga Otoritas Jasa Keuangan (OJK) menetapkan ketentuan suku bunga single digit sehingga bank dituntut harus efisien. Ada tiga komponen pembentuk suku bunga kredit, yakni harga pokok dana, biaya operasional (overhead) dan marjin keuntungan (profit margin). Harga pokok dana adalah biaya yang dikeluarkan bank untuk membayar bunga simpanan (dana pihak ketiga/DPK) seperti tabungan, deposito, dan giro. Harga pokok dana juga termasuk biaya dana dan biaya regulasi. Agar bunga kredit bisa turun, maka besaran komponen-komponen itu harus diturunkan. Komponen yang disasar pemerintah, BI, dan OJK untuk diturunkan adalah harga pokok dana dan biaya overhead mengingat kedua komponen tersebut masih bisa dioptimalkan (Suseno, 2008).

PT. Bank Rakyat Indonesian (Persero), Tbk (BRI) merupakan salah satu Bank BUMN yang juga dikenal sebagai salah satu bank tertua di Indonesia yang didirikan sejak Tahun 1985 merupakan salah satu bank yang konsisten dalam melakukan pemberian kredit bagi sektor usaha mikro, kecil dan menengah (UMKM) yang tersebar hampir di seluruh propinsi di Indonesia. Pertumbuhan kredit BRI yang dimotori oleh segmen UMKM merupakan fokus utama pengembangan bisnis 
di BRI. Portofolio pinjaman UMKM di BRI mencapai 91,80\% dari total portofolio kredit di BRI (BRI, 2015).

Penyaluran kredit ritel komersial dilayani 18 Kantor 1 (Wilayah sebagai koordinator), 453 Kantor Cabang dan 565 Kantor Cabang Pembantu di seluruh Indonesia. Meskipun penyaluran kredit di BRI tumbuh secara siginifikan namun dari Tahun 2010-2015 persentase pertumbuhan laba terjadi penurunan. Pada Tahun 2010-2011 pertumbuhan laba perseroan mencapai 32\%. Namun, pada Tahun 2014-2015 pertumbuhan laba hanya sebesar 4\%. Terlihat pada Gambar 1, terjadi penurunan pertumbuhan laba di BRI dari Tahun 20102015 .

Sebagai salah satu Kanwil, yaitu Kanwil Jakarta 3 masih belum dapat menyalurkan kredit secara optimal dibuktikan dengan keragaan kantor wilayah pada posisi Desember 2015, total outstanding Kredit Ritel Komersial seKanwil Jakarta 3 adalah sebesar Rp8.134 Trilyun (tercapai 91,39\% dari target Desember 2015). Penyaluran Kredit Ritel Komersial di Kanwil Jakarta 3 belum optimal apabila dibandingkan dengan Kanwil lain pencapaian outstanding penyaluran kredit ritel komersial seperti Kanwil Jakarta 1 sebesar 115,45\% dan Kanwil Surabaya sebesar 101,20\%. Penyaluran kredit ritel komersial dapat dikatakan optimal jika pencapaian outstanding mencapai lebih dari 100\%. Jika dilihat Realisasi debitur baru atas total Plafond kredit selama Tahun 2015 Kanwil Jakarta 3 sebesar Rp1.445 Milyar dan total outstanding sampai dengan Desember 2015 sebesar Rp1.312 Milyar dengan total tenaga pemasar sebanyak 319 Account Officer (AO) dan jumlah debitur baru sampai dengan Desember 2015 sebanyak 2.633 debitur. Meskipun sebenarnya Kanwil Jakarta 3 memiliki 36 Kantor Cabang yang tersebar di sebagian Jakarta, Banten, Tangerang dan Kalimantan Selatan namun belum optimal dalam menyalurkan kredit ritel komersial tersebut. Oleh sebab itu, tujuan dari penelitian ini adalah untuk menganalisis tingkat efisiensi penyaluran kredit ritel komersial terhadap sektor UMKM di BRI Kanwil Jakarta 3 dan mengetahui faktor-faktor yang memengaruhi efisiensi penyaluran kredit ritel komersial terhadap sektor UMKM di BRI Kanwil Jakarta 3.

\section{METODE}

Penelitian ini dilaksanakan di BRI Kanwil Jakarta 3 Jl. Dr. Soebianto Djojokusumo Kav. CBD II No 1 BSD Tangerang Selatan selama dua bulan, yaitu Bulan Agustus dan September 2016. Data yang digunakan ialah data sekunder berupa laporan penyaluran kredit ritel komersial terhadap sektor UMKM di BRI Kanwil Jakarta 3 periode end of year (EoY) 2013, 2014 dan 2015 dengan 36 Kantor Cabang di bawah supervisi Kanwil Jakarta 3. Pengumpulan data bertujuan untuk memperoleh informasi, gambaran dan keterangan tentang hal-hal yang berkaitan dengan materi penelitian sehingga data tersebut dapat dipergunakan untuk menganalisis setiap aspek yang dikaji.

Adapun data-data yang diperlukan dalam penelitian ini adalah sebagai berikut: Pemilihan DMU adalah unit-unit yang diukur dan dianalisis efisiensinya. Langkah kedua mengidentifikasi variabel-variabel yang berhubungan dengan variabel input dan output. Pengelompokkan variabel tersebut dimaksudkan untuk mempermudah perhitungan dan menganalisis variabelvariabel yang berpengaruh yang dapat diketahui dari input dan output yang dikelompokkan. Dalam proses identifikasi variabel input-output ditentukan dengan cara brainstorming dengan pihak perusahaan dan referensi penelitian sebelumnya. Sedangkan untuk faktor-faktor yang memengaruhi penyaluran kredit ritel adalah jumlah debitur, KUR ritel, pertumbuhan debitur ritel, total pinjaman KCP dan total pinjaman ritel selama tahun 2013, 2014, dan 2015.

\section{Data Envelopment Analysis (DEA)}

Metode DEA diperkenalkan oleh Charnes, Cooper, dan Rhodes (1978 dan 1989). Metode ini merupakan salah satu alat bantu evaluasi untuk meneliti kinerja dari suatu aktifitas dalam sebuah unit entitas. DEA adalah sebuah teknik pemrograman matematis yang digunakan untuk mengevaluasi efisiensi relative dari suatu kumpulan unit-unit pembuat keputusan (DMU) dalam mengelola sumber daya (input) dengan jenis yang sama sehingga menjadi hasil (output) dengan jenis yang sama pula, dimana hubungan bentuk fungsi dari input ke output diketahui. Analisis yang dilakukan berdasarkan kepada evaluasi terhadap efisiensi relatif dari DMU yang sebanding. Selanjutnya, DMU yang efisien tersebut akan membentuk garis fronlier. Jika DMU berada pada garis frontlier maka DMU tersebut dapat dikatan efisien relatif dibandingkan dengan DMU yang lain dalam 
peer-group-nya. Selain menghasilkan nilai efisiensi masing-masing DMU, DEA juga menunjukkan unitunit yang menjadi referensi bagi unit-unit yang tidak efisien.

Setelah dilakukan identifikasi variabel input dan output maka langkah selanjutnya membuat model matematis DEA. Menurut Ramanathan (2003), DEA adalah teknik berbasis program linier untuk mengukur efisiensi unit organisasi yang dinamakan DMU. Menurut Cooper et al. (2002), DEA menggunakan teknis program matematis yang dapat menangani variabel dan batasan yang banyak, dan tidak membatasi input dan output yang akan dipilih karena teknis yang dipakai dapat mengatasinya. DEA ditemukan pertama kali oleh Farrell pada tahun 1957 dan dikembangkan oleh Charnes et al. (1978) yang dikenal dengan model CCR. Dalam model ini, suatu tingkat efisiensi dihitung melalui rasio output terhadap input dengan pembobotannya masing-masing. Untuk menentukan bobot tersebut dilakukan dengan program linier. Program linier merupakan sebuah model matematis yang mempunyai dua komponen tujuan dan kendala. Fungsi tujuan (objective function) terdiri dari variabel-variabel keputusan. Variabel yang dipergunakan dalam pengukuran efisiensi pada Tabel 1.

\section{Regresi Data Panel}

Gabungan data cross section dan time series ini disebut data panel (panel pooled data). Regresi dengan menggunakan data panel disebut model regresi data panel. Terdapat beberapa keuntungan yang diperoleh dengan menggunakan data panel. Pertama, data panel yang merupakan gabungan dua data time series dan cross section mampu menyediakan data yang lebih banyak sehingga menghasilkan degree of freedom yang lebih besar. Kedua, menggabungkan informasi dai data time series dan cross section dapat mengatasi masalah yang timbul ketika adalah masalah penghilangan variabel (ommitted variabel) (Agus, 2009). Bentuk struktur persamaan model analisis data panel linier adalah sebagai berikut:

$$
\mathrm{Y}_{\mathrm{it}}=\beta_{0}+\beta \mathrm{X}_{\mathrm{it}}+\varepsilon_{\mathrm{it}}
$$

Dimana: i (unit cross section sebanyak $\mathrm{n}$ ); $\mathrm{t}$ (unit time series sebanyak t); Yit (variabel dependen untuk section $\mathrm{ke}-\mathrm{i}$ dan waktu $\mathrm{ke}-\mathrm{t}$ ); Eit = disturbance term mempunyai $\mathrm{E}($ Eit $)=0$.

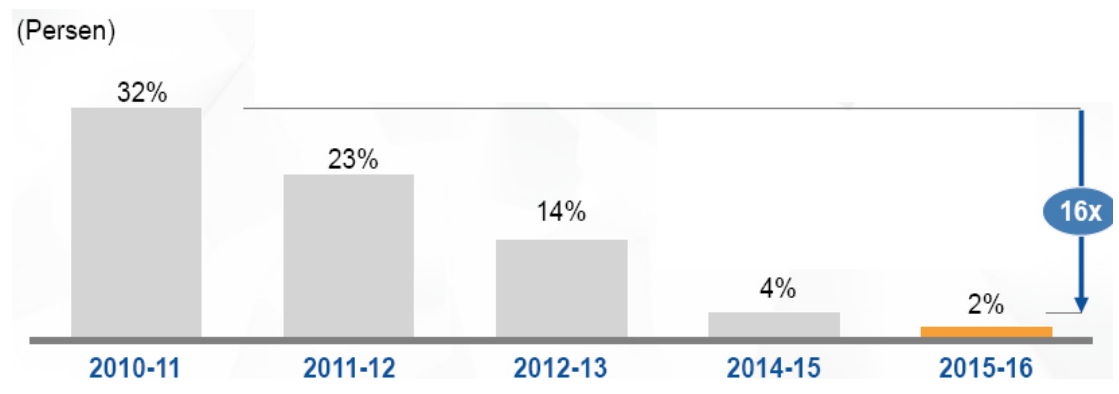

Gambar 1. Grafik penurunan laba BRI

Tabel 1. Variabel yang dipergunakan dalam pengukuran efisiensi

\begin{tabular}{lll}
\hline \multicolumn{1}{l}{ Input } & variabel & \\
\hline X1 & Biaya dana & Biaya bunga bagi nasabah simpanan \\
X2 & Biaya operasional & Biaya tenaga kerja marketing \\
X3 & Resiko pembiayaan (NPL) & Biaya pencadangan atas kredit bermasalah \\
Output variabel & \\
Y1 & Pertumbuhan kredit & Jumlah outstanding kredit ritel komersial \\
Y2 & Realisasi debitur baru & Jumlah outstanding nasabah baru \\
Y3 & Jumlah debitur UMKM & Total debitur yang menikmati kredit ritel \\
Y4 & Pencapaian target & Persentase outstanding kredit terhadap target \\
\hline
\end{tabular}


Secara matematis model panel data Fixed Effect tingkat efisiensi dapat ditulis sebagai berikut:

$$
\text { EFISIENSI }_{\mathrm{it}}=\beta_{0}+\beta_{1} \text { TAit }+\beta_{2} \mathrm{DPK}+\beta_{3} \mathrm{KYD}+\square \text { it }
$$

Dimana: i $(1,2,3, \ldots \ldots, \mathrm{n}) ; \mathrm{t}(1,2,3, \ldots, \mathrm{t}) ; \mathrm{TA}$ (Totalaset); DPK (Dana pihak ketiga); KYD (Kredityang diberikan); $\square \mathrm{it}($ disturbance term mempunyai $\mathrm{E}(\square \mathrm{it})=0$ ).

Namun, ada beberapa metode yang biasa digunakan untuk mengestimasi model regresi dengan data panel, yaitu pendekatan common effect, fixed effect dan random effect (Agus, 2009). Namun, dalam penelitian ini akan menggunakan pendekatan fixed effect.

\section{HASIL}

\section{Tingkat Efisiensi Penyaluran Kredit Ritel Komersial}

Hasil analisis statistik deskriptif dari variabel-variabel yang digunakan dalam empiris analisis meliputi mean dan standar deviasi. Pada variabel input, standar deviasi menunjukkan perbedaan yang cukup besar. Pada variabel input biaya dana (X1) antara DMU di tahun 2013, 2014, dan 2015, standar deviasi tertinggi terjadi pada tahun 2015. Pada variabel input biaya operasional (X2) antara DMU di tahun 2013, 2014, dan 2015, standar deviasi tertinggi terjadi pada tahun 2015. Pada variabel input risiko pembiayaan (X3) antara DMU di tahun 2013, 2014, dan 2015, standar deviasi tertinggi terjadi pada tahun 2014.

Pada variabel output, standar deviasinya juga menunjukkan perbedaan yang cukup besar. Pada variabel output pertumbuhan kredit (Y1) antara DMU di tahun 2013, 2014, dan 2015, standar deviasi tertinggi terjadi pada tahun 2015. Pada variabel output relialisasi debitur baru (Y2) antara DMU di tahun 2013, 2014, dan 2015, standar deviasi tertinggi terjadi pada tahun 2015. Pada variabel output jumlah debitur (Y3) antara DMU di tahun 2013, 2014, dan 2015, standar deviasi tertinggi terjadi pada tahun 2015. Statistik deskriptif variabel-variabel yang digunakan selengkapnya pada Tabel 2.

Tabel 3 menyajikan hasil pengolahan data dengan menggunakan DEA. Dengan menerapkan rasio keuangan untuk mengevaluasi risiko kredit. Pada Tabel 3, menunjukkan bahwa terdapat unit (unit Joglo, Sanggau, Singkawang, dan Tangerang) yang efisien dalam semua jenis efisiensi selama periode penelitian, karena semua nilai efisiensi yang sama dengan "1". Hasil penelitian menunjukkan bahwa 4 unit tersebut memiliki kinerja yang stabil. Ini juga merupakan bahwa unit tersebut memiliki kinerja yang lebih baik daripada yang lain.

Tabel 2. Statistik deskriptif variabel-variabel yang digunakan

\begin{tabular}{llrrr}
\hline \multirow{2}{*}{ Variabel } & & \multicolumn{3}{c}{ Tahun } \\
\cline { 3 - 5 } & & \multicolumn{2}{c}{2013} & \multicolumn{1}{c}{2014} \\
\hline Biaya dana (X1) (Rp) & Mean & 22.321 .589 .200 & 37.181 .366 .511 & 39.189 .920 .488 \\
& SD & 51.380 .777 .605 & 87.972 .525 .268 & 102.213 .861 .677 \\
Biaya operasional (X2)(Rp) & Mean & 3.666 .871 .695 & 4.456 .583 .694 & 5.123 .607 .945 \\
& SD & 1.696 .195 .850 & 1.863 .334 .180 & 1.883 .023 .862 \\
Resiko pembiayaan (X3) (Rp) & Mean & 6.362 .545 .067 & 7.203 .425 .578 & 7.776 .117 .243 \\
& SD & 7.446 .168 .521 & 9.305 .692 .461 & 8.506 .261 .655 \\
Pertumbuhan kredit (Y1) (Rp) & Mean & 109.602 .000 .000 & 98.851 .000 .000 & 111.677 .000 .000 \\
& SD & 465.062 .000 .000 & 378.851 .000 .000 & 473.004 .000 .000 \\
Relialisasi debitur baru (Y2) (debitur) & Mean & 218 & 227 & 257 \\
& SD & 108 & 107 & 113 \\
Jumlah debitur (Y3) (debitur) & Mean & 235 & 249 & 284 \\
& SD & 121 & 122 & 128 \\
Pencapaian target (Y4) (\%) & Mean & $171,99 \%$ & $320,87 \%$ & $165,57 \%$ \\
& SD & 2,859121 & 2,932916 & 2,854818 \\
\hline
\end{tabular}


Tabel 3. Hasil efisiensi dengan metode non parametrik DEA

\begin{tabular}{|c|c|c|c|}
\hline \multirow{2}{*}{ Unit } & \multicolumn{3}{|c|}{ Tahun } \\
\hline & 2013 & 2014 & 2015 \\
\hline Kota & 1 & 0,922877 & 1 \\
\hline Pandeglang & 0,794071 & 0,725891 & 0,774586 \\
\hline Pontianak & 0,621883 & 0,479714 & 0,597864 \\
\hline Rangkasbitung & 0,6907 & 0,728419 & 0,816762 \\
\hline Serang & 0,552105 & 0,655217 & 0,841731 \\
\hline Singkawang & 1 & 1 & 1 \\
\hline Tangerang & 0,850255 & 1 & 1 \\
\hline Labuan & 1 & 0,814492 & 0,733128 \\
\hline Cilegon & 0,904225 & 0,842732 & 0,83692 \\
\hline Mempawah & 0,542986 & 0,523692 & 0,664436 \\
\hline Ketapang & 0,506569 & 0,508759 & 0,646117 \\
\hline Sintang & 1 & 0,648146 & 0,681719 \\
\hline Putussibau & 0,626877 & 0,575567 & 0,620469 \\
\hline Sanggau & 1 & 1 & 1 \\
\hline Roxy & 0,42712 & 0,443057 & 0,337313 \\
\hline Kebon Jeruk & 0,2661 & 0,31451 & 0,35211 \\
\hline Daan Mogot & 0,268333 & 0,229076 & 0,279509 \\
\hline Ciputat & 0,659803 & 0,727709 & 0,863387 \\
\hline Ciledug & 0,420707 & 0,728498 & 0,726628 \\
\hline Bintaro & 1 & 0,896956 & 1 \\
\hline Tanjung Duren & 0,242336 & 0,332295 & 0,288958 \\
\hline Joglo & 1 & 1 & 1 \\
\hline Palmerah & 0,400052 & 0,221423 & 0,331709 \\
\hline Puri Niaga & 0,193733 & 0,304842 & 0,25655 \\
\hline Kalideres & 0,444387 & 0,627821 & 0,635354 \\
\hline S Parman & 0,327962 & 0,361237 & 0,406857 \\
\hline Jelambar & 0,26772 & 0,29251 & 0,196609 \\
\hline Balaraja & 1 & 1 & 0,906382 \\
\hline Tangerang City & 0,788407 & 1 & 0,793821 \\
\hline Tang Merdeka & 1 & 1 & 1 \\
\hline BSD & 0,341913 & 0,458025 & 0,496243 \\
\hline Pamulang & 0,494609 & 0,246488 & 0,46385 \\
\hline Bandara Soetta & 0,444769 & 0,332249 & 0,324556 \\
\hline Gading Serpong & 1 & 0,369913 & 0,355606 \\
\hline Gajahmada Pontianak & 1 & 1 & 0,318606 \\
\hline Melawi & 1 & 0,973136 & 0,832085 \\
\hline
\end{tabular}

Hasil dari penelitian ini menunjukkan bahwa tidak semua unit di kanwil Jakarta 3 yang menjadi sampel mencapai tingkat efisiensi pada penelitian periode tahun 2013-2015. Dengan menggunakan metode non parametrik DEA, dan variabel-variabel yang ditentukan, terdapat 23 unit yang tidak mencapai tingkat efisiensi. Unit tersebut adalah Pandeglang, Pontianak, Rangkasbitung, Serang, Cilegon, Mempawah, Ketapang, Putussibau, Roxy, Kebon Jeruk, Daan Mogot, Ciputat, Ciledug, Tanjung Duren,
Palmerah, Puri Niaga, Kalideres, S Parman, Jelambar, BSD, Pamulang, Bandara Soekarno Hatta atau dengan persentase sebesar $64 \%$ dari keseluruhan unit kanwil Jakarta 3 tidak mencapai tingkat efisiensi 100\%.

Unit-unit yang telah mencapai nilai efisiensi dalam tahun 2013-2015 antara lain unit Sanggau, Singkawang, Joglo dan Tangerang Merdeka secara konsisten telah dapat menyelesaikan pekerjaan dengan benar dengan menggunakan input yang minimal menghasilkan output 
yang semaksimal mungkin. Unit Sanggau, Singkawang, Joglo dan Tanggerang Merdeka mampu beroperasi dalam skala yang konstan, mampu beroperasi pada diversifikasi lokasi, efisiensi teknis (dimana suatu bank dalam menyatakan suatu hubungan antara input dan output pada proses produksinya) dan efisiensi alokasi (dimana agar efisiensi alokasi ini tercapai suatu bank harus mampu untuk menentukan berbagai output yang dapat memaksimalkan keuntungan).

Unit-unit yang pernah efisien walaupun tidak di setiap tahun periode penelitian sejumlah sembilan unit antara lain Kota, Tanggerang, Labuan, Sintang, Bintaro, Balaraja, Kota Tangerang, Gading Serpong, Gajahmada Pontianak.Unittersebutsudah mencapaitingkatefisiensi 1 pada tahun 2015. Adapun untuk unit yang pada tahun 2015 yang belum mencapai tingkat efisien sempurna, yaitu 1 (Pandeglang, Pontianak, Rangkasbitung, Serang, Cilegon, Mempawah, Ketapang, Putussibau, Roxy, Kebon Jeruk, Daan Mogot, Ciputat, Ciledug, Tanjung Duren, Palmerah, Puri Niaga, Kalideres, S Parman, Jelambar, BSD, Pamulang, Bandara Soekarno Hatta).

\section{Faktor-Faktor yang Memengaruhi Efisiensi}

Skor efisiensi yang diperoleh dengan menggunakan DEA selanjutnya akan dianalisis bersama-sama dengan menggunakan regresi panel dengan model random. Adapun persamaan dari model tersebut selengkapnya pada Tabel 4 .

Adapun interpretasi model persamaan regresi tersebut adalah sebagai berikut:

1. Nilai 10,31610 merupakan nilai konstanta (a), yang menunjukkan bahwa jika tidak ada variabel Total pinjaman ritel, total pinjaman KCP, KUR ritel, pertumbuhan kredit ritel, pertumbuhan debitur ritel dan jumlah debitur ritel nilai efisiensi penyaluran kredit UMKM mencapai 10,31610\%.
2. Nilai 0,003539 merupakan koefisien regresi yang menunjukkan bahwa setiap penambahan variabel total pinjaman ritel (X1) maka efisiensi penyaluran kredit UMKM akan bertambah sebesar 0,003539\% dengan asumsi variabel lainnya tetap (0). Dilihat dari koefisen regresi yang menunjukkan positif yang artinya dengan kenaikan total pinjaman ritel di bank BRI maka cenderung meningkatkan laba.

3. Nilai 0,353939 merupakan koefisien regresi yang menunjukkan bahwa setiap penambahan variabel Total Pinjaman KCP(X2) maka efisiensi penyaluran kredit UMKM akan berkurang sebesar 0,353939\% dengan asumsi variabel lainnya tetap (0). Dilihat dari koefisen regresi yang menunjukkan negatif yang artinya dengan kenaikan total pinjaman KCP bank BRI maka nasabah cenderung untuk meminimalisir transaksi-transaksi.

4. Nilai 0,112316 merupakan koefisien regresi yang menunjukkan bahwa setiap penambahan KUR Ritel (X3), maka efisiensi penyaluran kredit UMKM akan berkurang sebesar $0,112316 \%$ dengan asumsi variabel lainnya tetap (0). Dilihat dari koefisen regresi yang menunjukkan negatif yang artinya dengan kenaikan biaya pencadangan atas kredit bermasalah bank BRI maka nasabah cenderung untuk meminimalisir transaksi-transaksi setiap bulannya. Dilihat dari koefisen regresi yang menunjukan negatifyang artinya adalah semakin tinggi jangka waktu KUR Ritel maka risiko akan semakin besar baik dari kreditur maupun debitur, mengingat NPL dari BRI harus bisa mencapai target. Selanjutnya, menghindari terjadinya kredit macet dan moral hazard dari calon nasabah.

5. Nilai 0,000442merupakan koefisien regresi yang menunjukkan bahwa setiap penambahan pertumbuhan kredit ritel (X4) maka efisiensi penyaluran kredit UMKM akan bertambah sebesar 0,000442\% dengan asumsi variabel lainnya tetap (0). Dilihat dari koefisen regresi yang menunjukkan positif yang artinya dengan kenaikan Jumlah outstanding kredit ritel bank BRI maka nasabah cenderung untuk menambah transaksitransaksi setiap bulannya.

Tabel 4. Model regresi panel

\begin{tabular}{|c|c|c|c|c|}
\hline Variable & Coefficient & Std. Error & $t$-Statistic & Prob. \\
\hline $\mathrm{C}$ & 10,31610 & 1,167375 & 8,837008 & 0,0000 \\
\hline JUMDEBITUR & 0,003479 & 0,001985 & 1,752515 & 0,0843 \\
\hline KURRITEL & $-0,112316$ & 0,026974 & $-4,163824$ & 0,0001 \\
\hline PERTUMBDEBRITEL & $-0,001456$ & 0,002216 & $-0,656935$ & 0,5135 \\
\hline PERTUMBKREDITRITEL & 0,000442 & 0,000532 & 0,831491 & 0,4087 \\
\hline TOTPINJKCP & $-0,353939$ & 0,053459 & $-6,620782$ & 0,0000 \\
\hline TOTPINJRITEL & 0,003539 & 0,004453 & 0,794741 & 0,4296 \\
\hline
\end{tabular}


6. Nilai 0,000442merupakan koefisien regresi yang menunjukkan bahwa setiap penambahan realisasi debitur ritel (X5), maka efisiensi penyaluran kredit UMKM akan bertambah sebesar 0,000442\% dengan asumsi variabel lainnya tetap (0). Dilihat dari koefisen regresi yang menunjukkan positif yang artinya dengan kenaikan Jumlah outstanding debitur ritel bank BRI maka nasabah cenderung untuk menambahtransaksi-transaksi setiap bulannya.

7. Nilai 0,003479merupakan koefisien regresi yang menunjukkan bahwa setiap penambahan jumlah debitur ritel (X6), maka efisiensi penyaluran kredit UMKM akan bertambah sebesar 0,003479\% dengan asumsi variabel lainnya tetap (0). Dilihat dari koefisen regresi yang menunjukkan positif yang artinya dengan kenaikan total debitur yang menikmati kredit ritel bank BRI maka nasabah cenderung untuk menambah transaksi-transaksi setiap bulannya.

Dari hasil analisis yang telah dilakukan dengan menggunakan model regresi panel, dapat disimpulkan bahwa berdasarkan nilai signifikan faktor-faktor yang memengaruhi tingkat efisiensi perbankan, di antaranya adalah biaya operasional, NPL, pertumbuhan kredit dan relialisasi debitur.

\section{Implikasi Manajerial}

Hasil perhitungan analisis DEA dan hasil identifikasi faktor-faktor yang memengaruhi tingkat efisiensi Kanwil BRI Jakarta 3 dapat digunakan oleh manajemen BRI untuk melakukan evaluasi kinerja kanwil maupun DMU (Kantor Cabang) sehingga dapat menentukan langkah-langkah perbaikan dalam rangka meningkatkan efisiensi baik secara individu kantor cabang maupun kanwil. Adapun implikasi manajerial yang dapat menjadi masukan adalah Tingkat efisiensi kantor cabang dapat ditingkatkan dengan mengendalikan sisi input atau pengendalian biaya yang digunakan seperti meminimalkan risiko pembiayaan kredit dengan menyalurkan kredit yang sehat dan cepat menyelesaikan rasio kredit bermasalah. Dari sisi output yaitu perlu adanya peningkatan produktifitas dalam meningkatkan jumlah kredit dan meningkatkan jumlah debitur baru. Dengan produktifitas kredit yang optimal akan memberikan kontribusi laba bagi perusahaan dan juga dengan meningkatkan jumlah debitur baru dapat menyebar risiko bagi bank karena semakin beragam.

\section{KESIMPULAN DAN SARAN}

\section{Kesimpulan}

Kantor cabang (DMU) sebanyak 36 unit yang dianalisis terdapat emapat DMU, yaitu Joglo, Sanggau, Singkawang dan Tangerang Merdeka telah mencapai nilai efisiensi dalam Tahun 2013-2015. Di samping itu, secara konsisten dapat menyelesaikan pekerjaan dengan benar dengan menggunakan input yang minimal menghasilkan output yang semaksimal mungkin. Unit kerja tersebut memiliki manajemen risiko kredit yang baik dan kinerjanya stabil. Ini juga merupakan bahwa unit tersebut memiliki kinerja yang lebih baik daripada yang lain. Selain itu terdapat 11 unit yang pernah efisien walaupun tidak di setiap tahun periode penelitian dengan persentase sebesar $64 \%$ dari keseluruhan unit kanwil Jakarta 3 tidak perrnah mencapai tingkat efisiensi $100 \%$. Dari hasil analisis yang telah dilakukan dengan menggunakan model regresi panel, dapat disimpulkan bahwa berdasarkan nilai signifikan faktor-faktor yang memengaruhi tingkat efisiensi Kanwil Jakarta 3, di antaranya adalah biaya operasional, NPL, pertumbuhan kredit dan realisasi debitur dibandingkan.

\section{Saran}

Agar dapat memberikan hasil analisis yang lebih baik, dalam penelitian selanjutnya dapat memberikan jumlah pengamatan yang besar, meningkatkan degree of freedom (derajat kebebasan), data memiliki variabilitas yang besar, dapat memberikan informasi yang lebih banyak sehingga dapat memberikan hasil analisis yang lebih baik.

\section{DAFTAR PUSTAKA}

Abidin Z, Endri. 2009. Kinerja efisiensi teknis bank pembangunan daerah: pendekatan data envelopment analysis (DEA). Jurnal Akuntansi dan Keuangan 11(1): 21-29.

Agus W. 2007. Ekonometrika Teori dan Aplikasi untuk Ekonomi dan Bisnis, Edisi Kedua, Cetakan Kesatu. Yogyakarta: Penerbit Ekonisia Fakultas Ekonomi UII Yogyakarta

Beccalli E, Casu B, Girardone C. 2007. Efficiency and stock performance in european banking. Journal of Business Finance and Accounting 33: 245-262. https://doi.org/10.1111/j.14685957.2006.01362.x. 
Bonin JP, Hasan I, Paul W. 2005. Bank performance, efficiency and ownership in transition countries. Journal of Banking \& Finance 29(1): 31-53. https://doi.org/10.1016/j.jbankfin.2004.06.015.

Boot AW, Schmeijts A. 2005. The competitive challenge in banking. Working Paper 8: 1-39.

BRI. 2015. Laporan Tahunan BRI 2015. www.bri.co.id [26 Februari 2017].

Charnes A, Cooper WW, Rhodes E. 1978. Measuring the efficiency of decision making units. European Journal of Operational Research 2(6): 429-444.

Charnes A, Cooper WW, Rhodes E. 1989. Some models for estimating technical and scale inefficiencies in data envelopment analysis. Management Scdiences 30(9): 1078-1092. http://dx.doi. org/10.1287/mnsc.30.9.1078.

Cooper WW, Seiford LM, Tone K. 2002. Data Envelopment Analysis: A Comprehensive Text with Models, Applications, References and DEA Solver Software. Kluwer: Academic Publishers.

Dong F, Allen F. 2004. Technical and scale efficiencies for chinese rural credit cooperatives: a bootstrapping approach in data envelopment analysis. CARD Working Paper 403.

Fitria N, Sari RL. 2012. Analisis kebijakan pemberian kredit dan pengaruh non performing loan terhadap loan to deposit ratio pada PT. Bank Rakyat Indonesia (Persero), Tbk Cabang Rantau, Aceh Tamiang. Jurnal Ekonomi dan Keuangan 1(1):88-101.

Gaganis C, Liadaki A, Doumpos M, Zopundis C. 2009. Estimating and analyzing the efficiency and productivity of bank branches. Evidence form Greece, Managerial Finance 35(2): 202-218. https://doi.org/10.1108/03074350910923518.

Giokas DI. 2008. Cost efficiency impact of bank branch characteristics and location. Managerial Finance 34(3): 172-185. https://doi. org/10.1108/03074350810848054.

Hafidz J, Rachmanira S, Octi T. 2013. Tingkat persaingan dan efisiensi bank umum dan BPR di pasar kredit mikro di Indonesia. Working Paper 4(1803): 1-46.

Harjum M, Puspitasari R. 2007. Analisis perbandingan efisiensi bank syariah di Indonesia dengan metode data envelopment analysis (Periode tahun 2005). Jurnal Ekonomi dan Bisnis Islam 2(3): 80-116.
Heriyaldi, Yusuf AA. 2013. Does micro finance institution improve welfare ? a double difference analysis of Indonesian Community-Level Data. 201307. Bandung. http://lp3e.fe.unpad.ac.id/ wopeds/201307.pdf.

Kirkwood J, Nahm D. 2007. Australian banking efficiency and its relation to stock returns. The Economic Record 82: 253-267. https://doi. org/10.1111/j.1475-4932.2006.00338.x.

Kurnia AS. 2004. Mengukur efisiensi intermediasi sebelas bank terbesar indonesia dengan pendekatan Data Envelopment Analysis (DEA). Jurnal Bisnis Strategi 13(2): 126-140.

Manurung M, Prathama R. 2004. Uang, Perbankan, dan Ekonomi Moneter. Jakarta: Penerbit Fakultas Ekonomi Universitas Indonesia.

Mashal A, Ahmed E. 2015. Effects of TQM practices on banking sector performance: the case of Jordan. Journal of Applied Finance \& Banking 5 (6): 113-126.

Pratama PF. 2011. Analisis efisiensi bank umum persero di Indonesia.[tesis]. Bogor: Institut Pertanian Bogor.

Ramanathan R. 2003. An Introduction to Data Envelopment Analysis: a Tool for Performance Measurement. New Delhi: Economic Journal Publications.

Reddy YV. 2004. Banking sector in global perspective. Bankers Conference 2004. New Delhi: Economic Journal Publications.

Schaek K, Cihak M. 2008. How does competition affect efficiency and soundness in banking? new empirical evidence. Working Paper 932.

Sufian F, Majid MZA. 2007. Singapore banking efficiency and it's relation to stock returns: a DEA window analysis approach. International Journal of Bussines Studies 15 (1): 83-106.

Suseno P. 2008. Analisis efisiensi dan skala ekonomi pada industri perbankan syariah di Indonesia. Jurnal Ekonomi Islam 2(1).

Wardani S. 2011. Analisis pengaruh spread tingkat suku bunga bank, CAR, dan NPL. Jurnal Ekonomi Islam 5(1).

Widyastuti RS, Armanto B. 2013. Kompetisi industri perbankan Indonesia. Buletin Ekonomi Moneter dan Perbankan15(4): 417-439. https://doi. org/10.21098/bemp.v15i4.74.

Zenios CV, Zenios SA, Agathocleus K, Soteriou AC. 1999. Benchmarks of the efficiency of bank branches. Interface 29 (3): 37-51. 